\title{
BASELINE CHARACTERISTICS OF PATIENTS AND THE EFFECT OF FIXED-DOSE COMBINATION CHEMOTHERAPY ON SPUTUM CONVERSION TIME IN ACTIVE PULMONARY TUBERCULOSIS: A Preliminary Study in Kandy District, Sri Lanka
}

\author{
Jayawardena K. A. S., Samarathunga M.
}

District Chest Clinic Kandy, Sri Lanka

\begin{abstract}
Main Objective: To evaluate the effect of Fixed-Dose Combination (FDC) drugs on sputum conversion time in active tuberculosis.

Method: A prospective study of 58 active pulmonary tuberculosis patients in Kandy District Sri Lanka.

Results: The mean sputum conversion time was 3.836 weeks (SD 2.599) and the median was 4.00 weeks. The sputum conversion rate at the end of 8 weeks was $96.36 \%$. Initial bacillary load indicated by sputum smear grading was highly correlated with sputum conversion time $(r=0.531 P=0.000)$. Gender was associated with sputum conversion time. Women had significantly shorter sputum conversion time. ( $T$ value $=2.23, P=0.03, \mathrm{Df}=48$ ). Heavy smoking was associated with delayed sputum conversion in male patients $(p=0.01)$.

Conclusion: Use of FDC in active pulmonary tuberculosis yields high sputum conversion rate with a mean sputum conversion time of 3.4 weeks. Faster sputum conversion among women may be attributed to their stronger genetic constitution and healthy lifestyles. Heavy smoking is associated with delayed sputum conversion.
\end{abstract}

Key words: FDC Drugs; sputum conversion time; pulmonary tuberculosis; Sri Lanka;

\section{Introduction}

Tuberculosis (TB) remains as a significant public health problem in Sri Lanka. Every year there are $8000-10,000$ new cases and about 300 deaths of tuberculosis are reported by the national TB control programme in the country. ${ }^{1}$ Sri Lanka implemented Directly Observed Treatment Short course (DOTS) in the national

TB control programme in 1997. One key element of DOTS strategy is the use of short course chemotherapy regime under direct observation. This ensures patients taking right drugs in correct doses at correct intervals for correct period of time.
FDC drugs are said to be a quality combination of Anti-TB drugs in a single tablet. FDC simplifies the administration of drugs in many ways. Patients have fewer tablets to swallow, which in turn improve their compliance. Having fewer tablets to handle, supervision of drug intake becomes quicker. FDC also reduces potential prescription and counting errors of health care workers administering DOTS. If treatment is not observed, patients cannot be selective in the choice of drugs to ingest. With FDC ordering of drugs, storage, and stock control is simple and time saving. From the programme point of view, calculating drug needs, procurement, distributing and stoking throughout the programme will become simpler and probably be cost effective. WHO 
strongly recommends the use of FDC drugs for treatment of tuberculosis. ${ }^{2}$ In the year 2005, FDC drugs were introduced to Sri Lanka. A study conducted in Taiwan Su and Perng have found that FDC was equally effective as separate drugs in the management of active pulmonary tuberculosis. ${ }^{3}$

It is stated that patients soon become noninfectious when they are started on anti TB treatment. How soon a patient becomes noninfectious is a frequently ask question by health care workers and family members of the patients when they are asked to take care of patients. Sputum conversion time is a rough measure of the period of infectiousness. It is generally accepted that a patient with a long sputum conversion time transmits the disease for a longer period. Use of FDC drugs in DOTS is a new experience to Sri Lanka. Since its introduction, these drugs have been extensively used by the doctors in TB control. To our knowledge, no information is available about the effect of FDC chemotherapy on sputum conversion time in Sri Lankan patients.

The main objective of this study was to evaluate the effect of FDC chemotherapy on sputum conversion time in active pulmonary tuberculosis. In addition this study attempted to find out the association between sputum conversion time with some selected patients' characteristics. We believe that the results of this preliminary study will help to disseminate the knowledge among doctors with regard to the pattern of sputum conversion time with FDC drugs and other factors associated with it. It is also hoped that the experience and information obtained from this study will serve as a basis for a large scale study in future.

\section{Method}

\section{Design and set up}

This is a prospective study of smear positive PTB patient who were started on anti TB treatment at the District chest clinic Kandy. This clinic is the second largest TB control unit in Sri Lanka and serves as a training centre in respiratory medicine as well.
Sample size and method of sampling

All PTB smear positive patients who started treatment and registered for follow up in the chest clinic Kandy from 1.10.2006 to 31.12.2006 were selected. Following categories of patients were excluded from the study.

- Patients who started treatment out side and transferred to the chest clinic Kandy.

- Patients who interrupted treatment due to adverse effects of drugs and other reasons.

- Patient who started treatment at the chest clinic Kandy and transferred out to other districts.

\section{Data collection}

An interviewer administered structured questionnaire was used to collect patient's information. With informed voluntary consent, each patient's demographic profile, potential risk factors, weight, height, results of pre treatment and follow up investigations were all collected and recorded.

Patients were diagnosed as PTB smear positive when they were found positive for acid fast bacilli after examining three sputum samples. Spot, early morning and spot sputum samples were collected for direct sputum smear microcopy from each TB suspect for the diagnosis. Follow up sputum examinations were done weekly intervals after starting anti TB treatment. Two sputum samples (early morning and spot) were examined at each visit. Once a patient was found negative for AFB, at least one set of sputum sample was examined again at the following week to confirm the results. In addition, sputum samples of all patients in the study group were again tested routinely at the end of intensive phase of the treatment. All sputum examinations were done at the chest clinic sputum microscopy lab by qualified staff adhering to WHO recommended procedures. Positive sputum smears were graded using standard counting techniques. ${ }^{4}$ The AFB grading was recorded as scanty, 1+, 2+, and $3+$ according to the bacterial count observed in the oil immersion 
field. Body Mass Index (BMI) categorization was done using standard reference values for different age groups. ${ }^{5}$ Patients were reviewed at weekly intervals at the District chest clinic while they were on directly observed treatment daily at respective DOTS centres.

\begin{tabular}{|c|c|c|c|}
\hline Week & $\begin{array}{c}\text { Number } \\
\text { converted }\end{array}$ & $\begin{array}{l}\text { Cumulative } \\
\text { frequency }\end{array}$ & $\begin{array}{l}\text { Cumulative } \\
\%\end{array}$ \\
\hline 01 & 15 & 15 & 27.27 \\
02 & 4 & 19 & 34.55 \\
03 & 7 & 26 & 47.27 \\
04 & 11 & 37 & 67.27 \\
05 & 7 & 44 & 80.00 \\
06 & 1 & 45 & 81.82 \\
07 & 2 & 47 & 85.45 \\
08 & 6 & 53 & 96.36 \\
09 & 0 & 53 & 96.36 \\
10 & 2 & 55 & 100.00 \\
\hline
\end{tabular}

\section{Data analysis}

Data were entered and analyzed using Minitab computer software package. Statistical analysis was performed using correlation analysis, $t$ tests, and $\chi^{2}$ test whenever appropriate. $P$ value of $<0.05$ was considered statistically significant.

\section{Results}

A total of 58 PTB smear positive patients were selected and regularly followed up for the study. Three patients died during the period of follow up. Six patients belonged to the category II treatment regimen.

Table 1 Demographic Characteristics of patients $(n=58)$

Table 2 Distribution of patients by level of Body Mass Index (BMI) n=55

\begin{tabular}{|l|c|c|}
\hline \multicolumn{1}{|c|}{ BMI } & Frequency & $\%$ \\
\hline Normal & 8 & 14.6 \\
Low & 18 & 32.7 \\
Very low & 29 & 52.7 \\
\hline
\end{tabular}

Table 3 Smoking and alcohol consumption pattern among males $(n=38)$

\begin{tabular}{|l|l|l|l|}
\hline Factor & $\begin{array}{l}\text { Alcohol } \\
\text { addict }\end{array}$ & $\begin{array}{l}\text { Occasional or } \\
\text { non-drinker }\end{array}$ & Total \\
\hline Heavy & 13 & 9 & 22 \\
smoker & 7 & 9 & 16 \\
Mild or & 20 & 18 & 38 \\
non- \\
smoker & & & \\
Total & & & \\
\hline$X^{2}=0.87, P=0.35$
\end{tabular}

Table 4 Distribution of patients by the AFB grading of pre-treatment sputum smear results $(n=58)$

\begin{tabular}{|l|c|c|}
\hline AFB Grading & Frequency & Percentage \\
\hline Scanty & 6 & 10.3 \\
One + & 27 & 46.6 \\
Two + & 11 & 19.0 \\
Three + & 14 & 24.1 \\
\hline
\end{tabular}

Table 5 Results of weekly sputum smear examination (Cat I \& II combined)

Mean $=3.83$ weeks \pm 2.55

Median $=4$ weeks

Table 6 Results of weekly sputum smear examination (Cat II)

\begin{tabular}{|l|l|l|}
\hline \multicolumn{1}{|c|}{ Variable } & \multirow{2}{*}{ Frequency } & \% \\
\cline { 1 - 2 } Age Group & 01 & 1.72 \\
$0-15$ & 15 & 25.86 \\
$16-30$ & 14 & 24.14 \\
$31-45$ & 17 & 29.31 \\
$46-60$ & 10 & 17.72 \\
$61-75$ & 01 & 1.72 \\
$>75$ & & \\
Sex & 38 & 65.52 \\
Male & 20 & 34.48 \\
Female & & \\
Ethnic Group & 41 & 70.69 \\
Sinhala & 09 & 15.52 \\
Tamil & 08 & 13.79 \\
Moor & & \\
Level of education & & 14 \\
Not gone to school & 08 & 24 \\
Primary (Gr1-5) & 14 & 60 \\
Secondary (Gr6-12) & 35 & 02 \\
Higher & 01 & \\
\hline
\end{tabular}


Mean $=2.67$ weeks \pm 2.73

Table 7 Correlation between selected quantitative variables and sputum conversion time

\begin{tabular}{|l|l|l|}
\hline Variable & $\begin{array}{l}\text { Pearson's } \\
\text { Correlation coefficient }\end{array}$ & $P$ \\
\hline Age & 0.027 & 0.847 \\
Sputum grading & 0.531 & 0.000 \\
BMI & 0.103 & 0.461 \\
\hline
\end{tabular}

Table 8 Difference between mean sputum conversion times between two sexes

\begin{tabular}{|l|l|l|l|l|}
\hline Sex & $\mathrm{n}$ & Mean & $\mathrm{SD}$ & SE mean \\
\hline Male & 36 & 4.3 & 2.7 & 0.45
\end{tabular}

\begin{tabular}{|c|c|c|c|}
\hline Week & $\begin{array}{l}\text { Number } \\
\text { converted }\end{array}$ & $\begin{array}{l}\text { Cumulative } \\
\text { frequency }\end{array}$ & $\begin{array}{l}\text { Cumula } \\
\text { tive } \\
\%\end{array}$ \\
\hline 01 & 3 & 3 & 50 \\
\hline 02 & 1 & 4 & 66.66 \\
\hline 03 & 1 & 5 & 83.33 \\
\hline 04 & 0 & 5 & 83.33 \\
\hline 05 & 0 & 5 & 83.33 \\
\hline 06 & 0 & 5 & 83.33 \\
\hline 07 & 0 & 5 & 83.33 \\
\hline 08 & 1 & 6 & 100.00 \\
\hline Female & 19 & 1.9 & 0.45 \\
\hline
\end{tabular}

$T$ value $=2.23, P=0.030, \mathrm{Df}=48$

Table 9 Associating of sputum conversion time (SCT) with (a) smoking and (b) alcohol habits in males $(n=35)$

(a)

\begin{tabular}{|l|l|l|}
\hline Smoking & SCT high & SCT low \\
\hline Heavy smoking & 12 & 9 \\
\hline Mild or non-smoking & 2 & 12 \\
\hline \multicolumn{2}{|c|}{$X^{2}=6.42, P=0.011$} \\
\hline
\end{tabular}

(b)

\begin{tabular}{|l|l|l|}
\hline Alcohol habits & SCT high & SCT low \\
\hline Addict & 8 & 9 \\
\hline Non-addict & 6 & 12 \\
\hline
\end{tabular}

$X^{2}=0.68, P=0.47$

STC high - > 4 weeks

STC low $-<4$ weeks

\section{Characteristics of patients}

Table 01 shows demographic characteristics of patients. Of the total, $46(80 \%)$ of patients were between $16-60$ years. The mean age was 43.34 years $(S D=15.88)$. Male to Female ratio was 2:1.04. The mean ages for male and female were $44.6 Y$ and $40.8 Y$ respectively. Out of 58 patients $(60 \%)$ have had secondary school education.

Body Mass Index (BMI) was calculated and analyzed in relation to the ages of patients. Only $14.6 \%$ of patients had normal BMl corresponding to the age and 53\% were found well below the minimum reference levels (table 02).

None of the female patients had smoking and alcohol habits. Among the 38 male patients in the study group there were 22 (58\%) heavy smokers and 20 (53\%) alcohol addicts (table 03). Statistics revealed that heavy smoking is not associated with alcohol addiction $\left(X^{2}=\right.$ $0.87, \mathrm{P}=0.35)$.

\section{Analyses of initial bacillary load}

Out of pre treatment positive sputum smear microscopy results, the highest positive grading of each patient was recorded for analysis. Twenty seven (46.6\%) patients belonged to the one + category (table 04).

\section{Sputum Conversion Time}

Out of 58 patients selected, sputum conversion was analyzed in 55 patients using weekly sputum microscopy examination results. Of all follow up patients including category II patients, 37 (67.27\%) had sputum conversion at the end of $4^{\text {th }}$ week, $53(96.36 \%)$ at the end of $8^{\text {th }}$ week, and the remaining 2 (3.64\%) completed sputum conversion at the end of $10^{\text {th }}$ week (table 05). The mean sputum conversion time was 3.836 weeks (SD: 2.559) and the median was 4.00 weeks. Sputum conversion pattern of category II patients ${ }^{6}$ was then separately analyzed and found that all had converted negative within 8 weeks of treatment (table 06). 


\section{Factors associated with sputum conversion}

Correlation coefficient analysis was performed to find associations between sputum conversion time and selected quantitative variables (table 07). Initial bacillary load measured by pre-treatment sputum smear grading showed a significant positive correlation with the sputum conversion time ( $r$ $=0.53$ ). Student $t$ test was applied to analyze the difference of sputum conversion times between two sexes (table 08). Male patients showed significantly longer sputum conversion time than female $(P=0.03)$.

Effect of heavy smoking and alcohol addiction on sputum conversion time was assessed in 35 male patients in the study group (table 09). Heavy smoking showed a significant association with delayed sputum conversion time $\left(X^{2}=6.42, P=0.01\right)$.

\section{Discussion}

Pulmonary Tuberculosis (PTB) is the commonest form of tuberculosis and is transmitted by airborne route. Patients with active pulmonary tuberculosis who have large number of bacilli in the lungs are the main source of the disease in the community. ${ }^{6}$ Isolation of acid fast bacilli by direct smear sputum microscopy is the most important method of diagnosis of pulmonary tuberculosis. After initiating anti TB therapy, the bacilli population will gradually decrease and it will come to a stage where the sputum direct smear will not yield a positive result for AFB. Disappearance of AFB from sputum smears has become the most accepted and widely used measurement of treatment response in active pulmonary tuberculosis.

Of our sample of 58 patients, male patients comprised nearly double the number of females confirming the usual sex distribution of smear positive PTB in the South-East Asia region. The age distribution however showed a peak case detection in the $46-60$ age group in contrast to that of the region remains 25-34 years. ${ }^{7}$ The observed difference may be at least partly due to the present aging population structure in Sri Lanka. This may also reflect the quality of implementation of TB control programme in Sri Lanka. A fair number of patients (60\%) have secondary school education reflecting high adult literacy rate in Sri Lanka. A large proportion of patients were found severely wasted as measured by BMI. None of the female patients were found either having a history of smoking or alcohol consumption. Such habits are culturally prohibited among Sri Lankan women. In contrast, there was high proportion of alcohol addicts and heavy smokers among male patients.

This study revealed that out of all sputum positive cases (cat I and II), sputum conversion rate at the end of eight weeks of FDC chemotherapy was $96.36 \%$. That was $92.0 \%$ for category I patients treated with separate drugs under directly observed treatment daily in the year 2003 in the same District. ${ }^{1}$ This suggests that there is at least a $4.0 \%$ increase in the sputum conversion rate with FDC drugs in contrast to that of separate drugs. The present study also revealed that the mean sputum conversion time was 3.8 weeks with $\mathrm{SD}=2.5$ weeks. In a similar study conducted in Spain with separate drugs, DominguezCastellano et al. have reported that it was 4.0 weeks with $\mathrm{SD}=2.7$ weeks. $^{8}$

It was found that gender is associated with sputum conversion time in addition to the observed difference in the incidence of TB between two sexes. Females showed a significantly shorter sputum conversion time. In comparison to males, females are genetically stronger, health conscious and less associated in high risk behaviours such as smoking and substance abuse. Such characteristics of females can be hypothesized as contributory factors for observed difference since there is no significant age difference seen between male and female TB patients in the group studied.

Among the quantitative variables analyzed in the present study, initial bacillary load 
measured by sputum smear grading showed a significant positive correlation with sputum conversion time. Similar observation has been reported in other studies. ${ }^{9,10}$ It has also been reported in another studies that age is significantly correlated with sputum conversion time.8,11 The present study did not show any such association.

It was observed that interruptions of treatment due to adverse effects were significantly low with FDC drugs during the study period though it was not objectively evaluated in this analysis. Three deaths that had occurred during the early part of the treatment were associated with late diagnosis and presence of complications such as severe bronchiactasis and diabetes mellitus. Better patient compliance and evidence of easy administration of drugs were also experienced with FDC during this study.

\section{Conclusions}

With FDC drugs under directly observed treatment, patients with active PTB become smear negative in 4 weeks on average. Heavy smoking significantly delays sputum conversion. The experience and findings obtained from this study would help to formulate a large scale evaluation of FDC chemotherapy on TB control in Sri Lanka.

\section{Acknowledgements}

We are grateful to the patients who participated in this study for their co-operation. We sincerely thank Dr. Anoma Siribaddana and Dr. Dushantha Medagedara, Consultant Chest Physicians, Kandy and Dr Chantha Jayawardena of University of Peradeniya for their encouragements and valuable advice. The assistance rendered by $C$. B. Amaranayaka (MRO), laboratory staff and
Medical Officers in the Chest Clinic Kandy are highly appreciated.

\section{References}

1 National Programme for Tuberculosis Control and Chest Disease. Administration Report 2004. Colombo: Ministry of Health Sri Lanka, 2004.

2 World Health Organization. Treatment of Tuberculosis: Guidelines for National Programmes. $3^{\text {rd }}$ ed. Genewa: WHO, 2003: 29.

3 Su WJ, Perng RP. Fixed-dose combination chemotherapy (Rifater $\AA /$ Rifinah $\AA$ ) for active pulmonary tuberculosis in Taiwan: a two-year follow-up. Int J Tuberc Lung Dis 2002; 11: 10291032.

4 Nair N. Diagnosis and Management. In Narayan JP; eds. Tuberculosis: Epidemiology and Control. $1^{\text {st }}$ ed. New Delhi: WHO Regional Office for SouthEast Asia; 2002: 47-50.

5 Gordon MW, Paul MI. Perspectives in Nutrition. $5^{\text {th }}$ ed. USA: WCB/McGrSW-Hill; 1996: 275.

6 Kumareson J. Epidemiology. In In Narayan JP; eds. Tuberculosis: Epidemiology and Control, $1^{\text {st }}$ ed. New Delhi: WHO Regional Office for SouthEast Asia; 2002: 16-17.

7 World Health Organization. Tuberculosis Control in the South-East Asia: The Regional Report 2005. New Delhi: WHO Regional Office for South-East Asia, 2005: 11-13.

8 Dominguez-Castellano A, Munian M.A, Rodriguez-Bano J, Garcia M, Rios MJ, Galvez J, Perez-Cano. Factors associated with time to sputum smear conversion in active pulmonary tuberculosis. Int J Tuberc Lung Dis 2003; 7: 432438.

9 Rieder HL. Sputum smear conversion during directly observed treatment for tuberculosis. Tuber Lung Dis 1996; 77: 124 -9.

10 Lienhardt $C$, Manneh $K$, Bouchier $V$ et al. Factors determining the outcome of treatment of adult smear positive tuberculosis cases in the Gambia. Int J Tuberc Lung Dis 1998; 2: 712-8.

11 Guler M, Unsal E, Dursun B, Aydin O, Capan N. Factors influencing sputum smear and culture conversion time among patients with new case pulmonary tuberculosis Int J clin Pract 2007; 61: $231-235$ 